\title{
APLICAÇÃO DE OSB - ORIENTED STRAND BOARD COMO MATERIAL PARA DESENVOLVIMENTO DE LOJA CONCEITO: ENFOQUE EM MOBILIÁRIO VERSÁTIL
}

\section{ORIENTED STRAND BOARD - OSB APPLICATION AS MATERIAL OF STORE CONCEPT DEVELOPMENT: FOCUS ON VERSATILE FURNITURE}

\author{
Eduardo Lima Martins (UNIFRA) \\ Mariana Piccoli, M.Sc. (UNIFRA) \\ Palavras Chave \\ Mobiliário, Loja Conceito; Material Ecologicamente Correto
}

\section{Key Words}

Furniture; Concept Store; Ecologically Correct Material

\section{RESUMO}

O presente trabalho procurou relacionar duas diferentes áreas: moda e design de interiores, no projeto do mobiliário para uma loja conceito de roupas transformáveis, com enfoque na versatilidade do mobiliário e na utilização de materiais ecologicamente corretos. Para sua realização, estudaram-se questões pertinentes relacionadas ao tema. Após pesquisa de diferentes materiais, definindo-se o OSB (Oriented Strand Board) como material a ser utilizado. A metodologia utilizada baseou-se em Bonsiepe (1984), complementada por um Design Centrado no Ser Humano (Human Centered Design - HCD, 2010), Löbach (2001) e Baxter (1998). Como resultados, desenvolveram-se seis móveis e utilizando retalhos de tecido como elemento de fixação ou detalhe.

\section{ABSTRACT}

The present work sought to relate two different areas: fashion and interior design, in the design of furniture for a concept store of transformable clothes, focusing on the versatility of furniture and the use of ecologically correct materials. For its accomplishment, pertinent questions related to the subject were studied. After researching different materials, the OSB (oriented strand board) was defined as the material to be used. The methodology used was based on Bonsiepe (1984), complemented by Human Centered Design (HCD, 2010), Löbach (2001) and Baxter (1998). As a result, six furniture were developed and fabric flaps were used as a fixation or detail element. 


\section{INTRODUÇÃO}

Entende-se por espaço comercial o ambiente que serve para a venda de produtos, e que nesse espaço circula um grande fluxo de pessoas, sejam elas vendedores, clientes e lojistas. Nesses locais, existe a necessidade de ressaltar as qualidades e características que a empresa tenha, como conceito, valores, quantidade de funcionários, público-alvo e produtos.

Cada atividade a ser desenvolvida dentro de um espaço comercial deve ser entendida por completo, desde os equipamentos e móveis que ocuparão aquele espaço, até a comunicação entre funcionários e clientes. E se um projeto for realizado sem um breve conhecimento das atividades comerciais, dos conceitos e valores da empresa, esse está direcionado a não realização e ao fracasso (GURGEL, 2005).

Para haver o planejamento de uma loja é necessário seguir alguns passos: primeiro, o desenho que é feito para o espaço, influencia e tem a capacidade de atrair atenção de seu público; segundo, esses espaços devem ser construídos de modo que não necessitem de ajustes frequentemente; terceiro, a loja representa o aspecto mais representativo da marca, a mesma cede uma vantagem diferente sobre as demais. Nesses sentidos já conhecidos, o planejamento de construção e execução do projeto influencia a ter grande alcance nos lucros da empresa (VARGAS, 2001).

De acordo com o site Viés Design (2014) loja conceito, concept store ou flagship store são espaços que exploram o máximo do conceito de uma loja/marca e são desenvolvidas para criar novas experiências ao cliente. Essas lojas mais do que oferecem produtos, elas contam a história da marca, comunicam o que há de diferente na marca e mostram os produtos de uma forma diferenciada.

Como exemplo, pode-se citar a marca de calçados Melissa, apresentada no Brasil pela gaúcha Grendene. Em agosto de 2005 a marca inaugurou a galeria Melissa, localizada em São Paulo, projetada por Muti Randolph, e revolucionou o conceito de flagship store, levando, além de produtos, conteúdo e cultura para suas instalações (MUNDO DAS MARCAS, 2006).

A galeria foi idealizada como um canal de comunicação e reúne diferentes colaboradores e inspirações. Imponente graças à sua fachada muito colorida (Figura 1) e constantemente renovada, a galeria tem o "jeito" da Melissa: dinâmica, moderna e sempre buscando novidades para assim, em plástico, construir sua história. A cada temporada a Melissa convida um artista para assinar a fachada da galeria (REVISTA GLAMOUR, 2014; MELISSA, 2016).
Figura 01: Modelos de fachadas da Galeria Melissa. (A) Power of Love; (B) Eat My Melissa; (C) Trópicos de Melissa; (D) Homenagem ao Rio de Janeiro

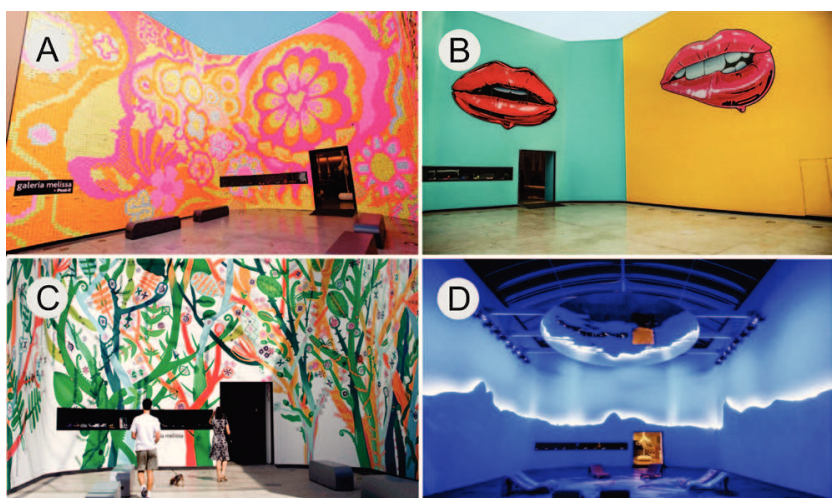

Fonte: (A) Make-up Case, 2015; (B) Clicrbs, 2014; (C) AndressaDoval, 2007; (D) Espelho Rosa Choque, 2015.

A proposta deste trabalho é desenvolver o mobiliário versátil, e aplicar em uma loja conceito para uma marca de roupas. Assim, buscou-se para ser estudo de caso uma marca que ainda não tivesse seu espaço físico de vendas, que fosse do Rio Grande do Sul e que envolvesse algum setor da moda; e a marca que aceitou participar deste projeto foi a OMINIMO, empresa criada recentemente, localizada em Porto Alegre - RS.

OMINIMO é uma marca de roupas transformáveis, ou seja, significa que todos os produtos da marca podem ser vestidos de mais de uma maneira, baseado no conceito da versatilidade dos produtos. Como apresentado na Figura 2, a modelo utiliza a mesma blusa de 20 maneiras diferentes. Assim o projeto focará no desenvolvimento do mobiliário desta marca.

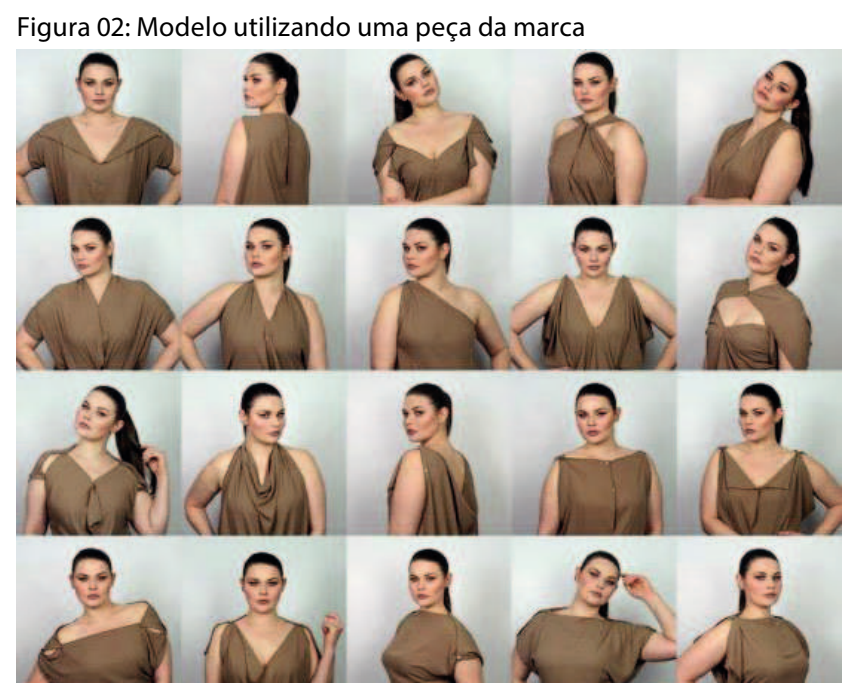

Fonte: OMINIMO, 2016.

O mobiliário que irá fazer parte da loja conceito deve atender ao mesmo conceito de versatilidade dos produtos 
da marca, o que significa que ele precisa adequar-se mais de um ambiente: além do espaço da loja em si, também em feiras itinerantes, modelo de venda de produtos que está tomando força.

O presente trabalho tem como objetivo aplicar os conhecimentos de design de produto no desenvolvimento de móveis versáteis, e definir o layout do ambiente de uma loja conceito para uma marca de roupas transformáveis, com enfoque na versatilidade do mobiliário e na utilização de materiais ecologicamente corretos.

\section{DESENVOLVIMENTO}

\subsection{Mobiliário Versátil}

Para que haja uma pluralidade de oferta, pode-se multiplicar e variar as maneiras de combinação dos móveis entre si, tornando-os multifuncionais ou versáteis. O potencial de mudança de um produto deve promover a criatividade do usuário, para que o mesmo faça uso do modo que desejar e esses possam ser intuitivos (KAZAZIAN, 2005, p. 46).

$\mathrm{O}$ produto multifuncional agrega outra função além da que está já pré-definida. De acordo com Piccoli (2011), na década de 1940 e especialmente nos anos pós-guerra, vários designers tiveram a preocupação de projetar em único objeto várias funções. Joe Colombo projetou uma cadeira multifuncional, a "Multichair" (Figura 3).

Figura 03: Multichair de Joe Colombo
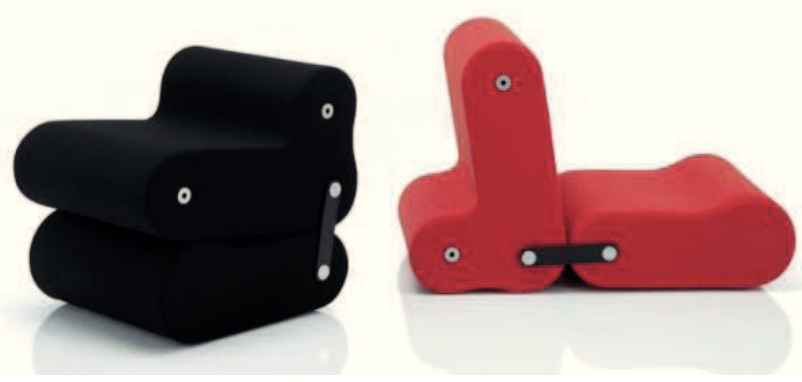

Fonte: Google Imagens, 2016.

\subsection{OSB - Oriented Strand Board}

O OSB é um material (Figura 4) formado pela aglomeração em camadas de lascas de madeira reflorestada, que são unidas por meio de colas a base de resina fenólica, ureia-formol e melamina, e depois são expostos à pressão e ao calor (LIMA, 2006, p. 108).
Figura 04: Placa de OSB

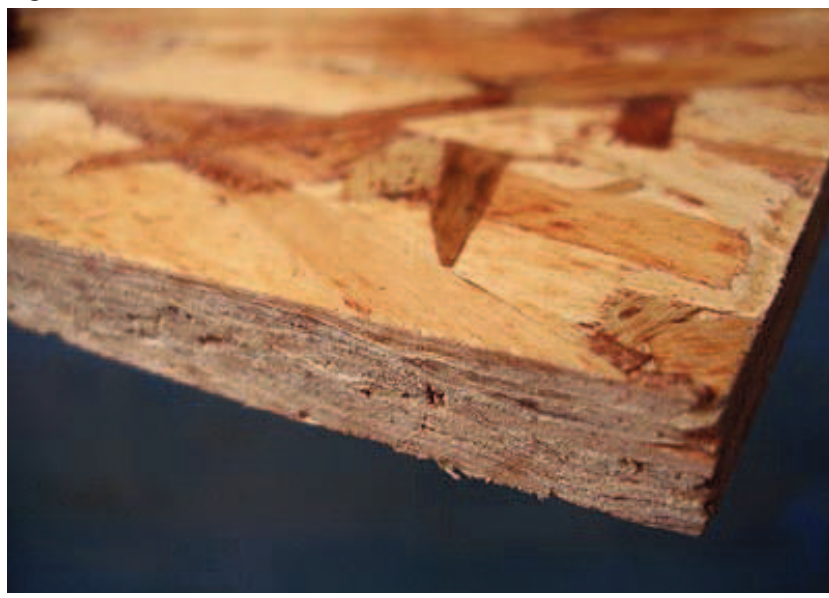

Fonte: Google Imagens, 2016.

Tem como características gerais a sua boa resistência mecânica, atua com isolante térmico e acústico, resistente ao fogo e geralmente encontrado nas medidas de 2440 x $1220 \mathrm{~mm}$ e em variadas espessuras 6, 8, 10, 15, 18 e 20 $\mathrm{mm}$. Suas aplicações são as mais variadas possíveis, desde a concepção de móveis, construção civil (nas paredes, Figura 5) e forros, e serve como base para a aplicação de carpetes e tapumes; pode ser usado para caixas de transporte, displays de vendas e também como estrutura para sofás (LIMA, 2006, p. 108).

De acordo com Hometeka (2016) "O procedimento industrial garante um elevado rendimento das matérias-primas. Cerca de 90\% do tronco de uma árvore pode ser convertido em OSB. As placas também são totalmente recicláveis, tornando o produto uma alternativa mais sustentável" sendo um dos materiais, desse estilo, mais sustentáveis que são utilizados para a construção de móveis.

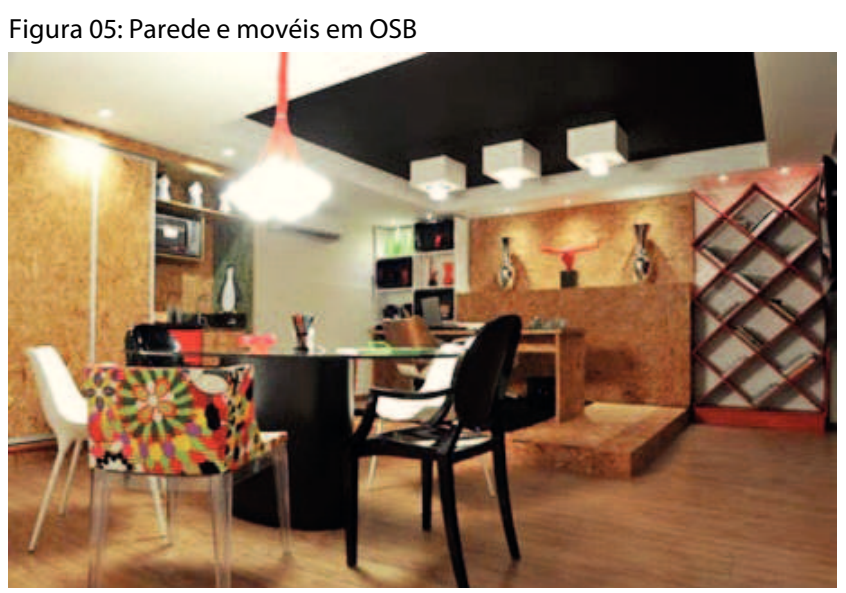

Fonte: Google Imagens, 2016c.

Os processos variam, pode ser cortado, mas o corte deve ser realizado com lâminas sólidas e bem afiadas, 
para que não ocorra a fragmentação das camadas de madeira. Embora, o OSB seja muito utilizado para estrutura de móveis, o mesmo pode ser utilizado também como material de acabamento. O OSB permite uma fixação bem fácil (LIMA, 2006, p. 109).

\subsection{Metodologia}

A metodologia utilizada no projeto segue os estudos de Bonsiepe (1984), complementado por Design Centrado no Ser Humano (Human Centered Design - HCD, 2010), Löbach (2001) e Baxter (1998). Essa metodologia se dá pelas seguintes etapas: problematização, entrevista com especialista, análise funcional, análise estrutural, análise de uso, análise semântica, análise ecológica, análise sincrônica, análise de materiais e processos, análise morfológica, análise ergonômica e lista de requisitos.

A entrevista com especialista traz informações especificas sobre o projeto a ser desenvolvido. A análise funcional é o momento em que se entende a função de cada produto e suas respectivas partes. $A$ análise estrutural apresenta tudo o que há no produto, como por exemplo, tipo de união e número de peças. A análise de uso compreende em observar o uso do produto pelos seus usuários, essa observação deve ser imperceptível e deve detectar os pontos negativos e positivos. Análise semântica deve mostrar todos os lados do produto e esse produto traga diferentes formas e traga sentimentos ao olhar (LÖBACH, 2001; BONSIEPE, 1984).

$\mathrm{Na}$ análise ecológica, apresentam-se os materiais que podem ser utilizados no projeto, como por exemplo, tintas ecologicamente corretas e os materiais alternativos mais adequados. O objetivo da análise sincrônica é reconhecer todo o universo do produto, desse modo reconhecendo marcas e preços e assim evitando reinvenções. A análise da necessidade faz uma pesquisa com o público alvo e futuros usuários do projeto. A análise de materiais e processos analisa os materiais que podem ser usados no projeto e todos os processos que nele são usados. A análise morfológica é aquela que compreende toda a estrutura formal do produto, informa sobre superfícies, cores e texturas; a análise ergonômica dá-se pela qualificação do projeto em sua correta forma em medidas e organização ergonômica, e finalizando a parte de pesquisas e análises, a lista de requisitos, essa vai definir como deve ser o produto que será desenvolvido (HCD, 2010; BONSIEPE, 1984).

Depois de realizadas as etapas de pesquisas e análises, realizam-se as etapas criativas, com a preparação de painéis semânticos, a fim de se definir os aspectos visuais do projeto. Então se vai para a geração de alternativas, e na sequência a realização e a seleção de alternativa (BAXTER, 1998).

Concluídas as etapas de pesquisas e a etapa da criação, inicia-se a fase final, de realização. Na parte técnica e prática do trabalho desenvolvem-se: o modelo física, que corresponde à modelagem física do projeto, o render virtual com ambientação, desenhos técnicos com lista de materiais utilizados, medidas e especificações, confronto dos requisitos e validação ergonômica, a fim de demonstrar se o resultado foi suficiente para o projeto (BONSIEPE, 1984).

\subsection{Problematização}

Por meio das perguntas Bonsipianas a seguir, estrutura-se e também se conhece um pouco mais sobre o problema a ser solucionado, o porquê esse problema foi escolhido e de que modo será solucionado.

Oquê?

Desenvolver os móveis versáteis, que se adequem a loja e feira, e aplicar em uma loja conceito, para uma marca de roupas transformáveis, com inspiração no minimalismo e no ecologicamente correto.

\section{Porquê?}

A moda e o design de interiores são relativamente próximos e quando são colocados juntos podem formar uma grande "parceria", dando resultado a um bom projeto. Conseguir aliar design de produto, espaço comercial e moda foi o motivo principal para o início deste projeto.

Como?

Através da metodologia de projeto de Bonsiepe (1984), complementada pelas metodologias de Design Centrado no Ser Humano (Human Centered Design - HCD, 2010), Löbach (2001) e Baxter (1998).

\subsection{Análise da Necessidade}

Para a realização da análise da necessidade foram seguidos alguns passos de acordo com o que Löbach (2001) mostra em sua metodologia. Entrevistas foram feitas de forma online com os possíveis futuros usuários da loja conceito da OMINIMO, marca escolhida para desenvolvimento deste projeto. Perguntas claras e objetivas foram criadas para serem aplicadas no questionário online.

As questões aplicadas, além de uma apresentação básica (sexo e faixa etária), eram relacionadas à própria marca: se o/a entrevistada/o possuía conhecimento da marca OMINIMO; interesse por peças transformáveis e se já haviam comprado peças da marca.

O questionário ficou disponível online durante duas semanas, foi compartilhado em redes sociais e enviado 
por e-mail. Foram entrevistadas 102 pessoas, sendo $91,2 \%$ do sexo feminino e $8,8 \%$ do sexo masculino. A faixa etária que mais respondeu foi de 19 a 25 anos, correspondendo a $46,1 \%$ dos entrevistados; de 26 a 35 anos foi de $23,5 \%$ e de 36 a 45 anos foi de 10,8\%.

Na pergunta em relação ao conhecimento, a maioria das pessoas respondeu que não conhece as marca, correspondendo a $52,9 \%$ dos entrevistados. Aos que responderam sim na pergunta de conhecimento da marca, $52,9 \%$ chegaram ao conhecimento da marca por meio de amigos, $39,2 \%$ pelas redes sociais, $2 \%$ por pesquisa e $5,9 \%$ respondera outros.

Quando questionado sobre compras na loja online da marca ou diretamente com o idealizador da marca $11,8 \%$ responderam que já haviam feito. Dos entrevistados $90,2 \%$ dizem ter interesse por peças com o mesmo conceito, transformável, da OMINIMO. Para ficar de melhor entendimento dessa análise, um infográfico (Figura 6) foi construído mostrando todos os pontos das entrevistas realizadas.

Figura 06: Infográfico realizado a partir de um questionário online

Desenvolvimento de uma loja
conceito para a marca $O M \mid M O M$

Fonte: Elaborado pelos autores, 2016.

\subsection{Análise Semiótica}

Para a análise semiótica, foram selecionados dois tipos de lojas. A loja A, é uma fast-fashion e apresenta uma enorme variedade de produtos, de peças e seu público alvo é muito amplo. Como pode-se observar na Figura 7, as portas da loja são bem grandes e cheias de propaganda, para que assim atrai o olhar de quem passa pela frente. A principal intenção dos proprietários deste tipo de loja é financeira, não havendo preocupação com quem vai usar a roupa que compra e nem onde essa roupa será utilizada. A iluminação é abundante, mas com alguns pontos de foco, geralmente esses são focados em peças mais caras da loja ou em acessórios.

Os preços das peças estão expostos em grandes placas, assim chamam a atenção para as peças mais baratas.
As vitrines geralmente são bem poluídas de informação, como por exemplo a grande quantidade de manequins, a abundância de placas com informações e o excesso de peças a mostra. As cores dessas lojas geralmente são as que mais chamam a atenção, com vermelho e azul.

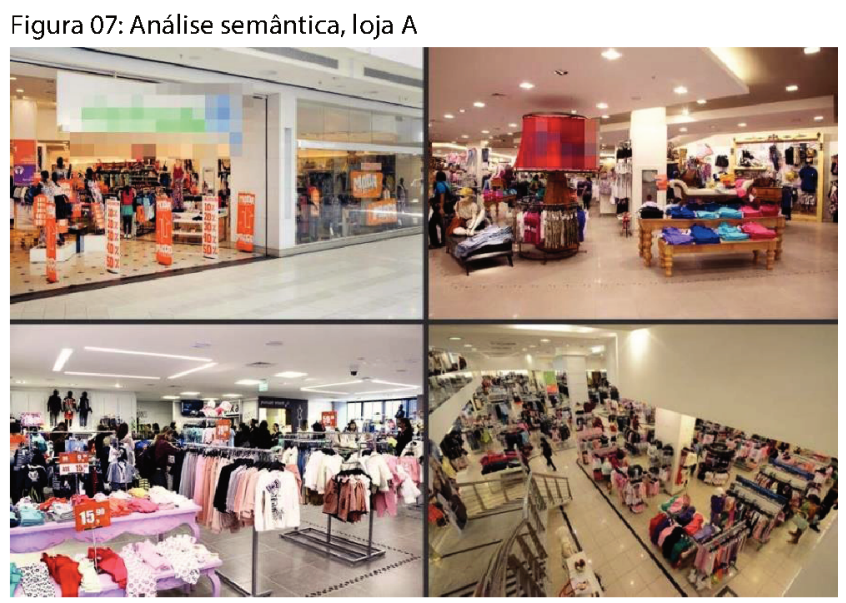

Fonte: Google Imagens, 2016.

Contrapondo as fast-fashion, as boutiques, loja B, são mais intimistas e procuram por um público mais seleto e já os tem bem definido. Como observado na Figura 8 , as vitrines são bem limpas e não possuem uma grande quantidade de produtos, peças e/ou acessórios.

A porta da loja é pequena, quando comparado as fast-fashion, desse modo agregando maior valor a loja. Os preços das roupas não são visíveis e muitas vezes não estão nas etiquetas das roupas, preços esses geralmente são elevados. As cores são neutras e a iluminação mais refinada.

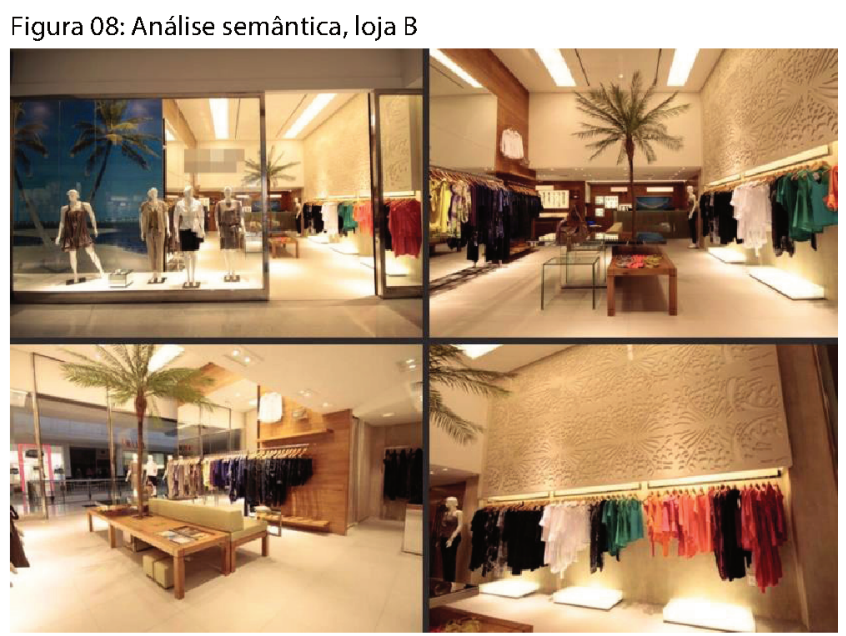

Fonte: Google Imagens, 2016.

Para o projeto da loja conceito da OMININO, busca-se por uma loja minimalista, como apresenta anteriormente na Figura 8. Busca-se também utilizar de poucas peças em 
exposição e de um atendimento mais exclusivo. As cores serão neutras, com pontos de destaque.

Para a criação dos painéis semânticos, uma pesquisa online foi realizada (pesquisa apresentada na análise da necessidade). Nela vários quesitos em relação à estética foram perguntados, e essas respostas geraram o diferencial semântico (Figura 9). Após soma da quantidade de pessoas que participaram e após o cálculo da média, três quesitos se destacaram, são eles: discreto, sóbrio e moderno.

Figura 09: Diferencial semântico

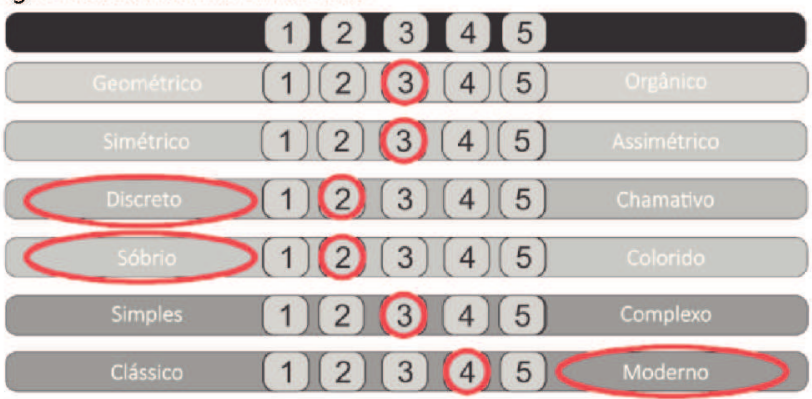

Fonte: Elaborado pelos autores, 2016.

\subsection{Lista de requisitos}

Neste ponto do projeto, algumas informações obtidas anteriormente, foram retomadas e agrupadas para que, a partir delas são estabelecidos os requisitos da loja conceito e do mobiliário que se pretende projetar.

A Tabela 1 apresenta os requisitos do projeto. Esses foram divididos em: requisitos estéticos, funcionais, ergonômicos, produtivos, semânticos e ecológicos, e separados em obrigatórios e desejáveis. Desse modo, o esforço para a concretização desse projeto, estará concentrado em atender as reais necessidades dos futuros usuários, e havendo a possibilidade de satisfazer os requisitos desejáveis.

Tabela 01: Lista de requisitos

(Continua)

\begin{tabular}{|c|c|c|}
\hline & Obrigatórios & Desejáveis \\
\hline Estéticos & $\begin{array}{l}\text { - Corresponder } \\
\text { ao tema visual, o } \\
\text { minimalismo } \\
\text { - Ter relação com as } \\
\text { palavras: discreto, } \\
\text { sóbrio e moderno } \\
\text { - Estética atemporal }\end{array}$ & $\begin{array}{l}\text { Monocromático } \\
\text { podendo ter } \\
\text { uma cor de } \\
\text { destaque }\end{array}$ \\
\hline
\end{tabular}

\begin{tabular}{|c|c|c|}
\hline & Obrigatórios & Desejáveis \\
\hline Funcionais & $\begin{array}{l}\text { - Transformável e } \\
\text { versátil } \\
\text { - Formato que permi- } \\
\text { te à diferentes confi- } \\
\text { gurações de uso } \\
\text { - Mobiliário ade- } \\
\text { quado às peças da } \\
\text { OMINIMO }\end{array}$ & $\begin{array}{l}\text { - Uso simples e } \\
\text { intuitivo }\end{array}$ \\
\hline Ergonômicos & $\begin{array}{l}\text { - Tamanho ergonomi- } \\
\text { camente adequado. } \\
\text { Formato que pro- } \\
\text { porcione o correto } \\
\text { armazenamento } \\
\text { dos produtos }\end{array}$ & \\
\hline Produtivos & $\begin{array}{l}\text { - Aproveitamento } \\
\text { máximo dos } \\
\text { materiais utilizados }\end{array}$ & \\
\hline Semânticos & $\begin{array}{l}\text { - Transmitir os valores } \\
\text { da marca }\end{array}$ & \\
\hline Ecológicos & $\begin{array}{l}\text { - Utilização de mate- } \\
\text { riais ecologicamente } \\
\text { corretos }\end{array}$ & \\
\hline
\end{tabular}

Fonte: Elaborado pelos autores, 2016.

\subsection{Desenvolvimento}

Para dar início o processo da geração de alternativas, utilizaram-se os painéis visuais de Baxter (1998), painel de estilo de vida, tema visual e expressão do produto, como pode ser visto na Figura 10.

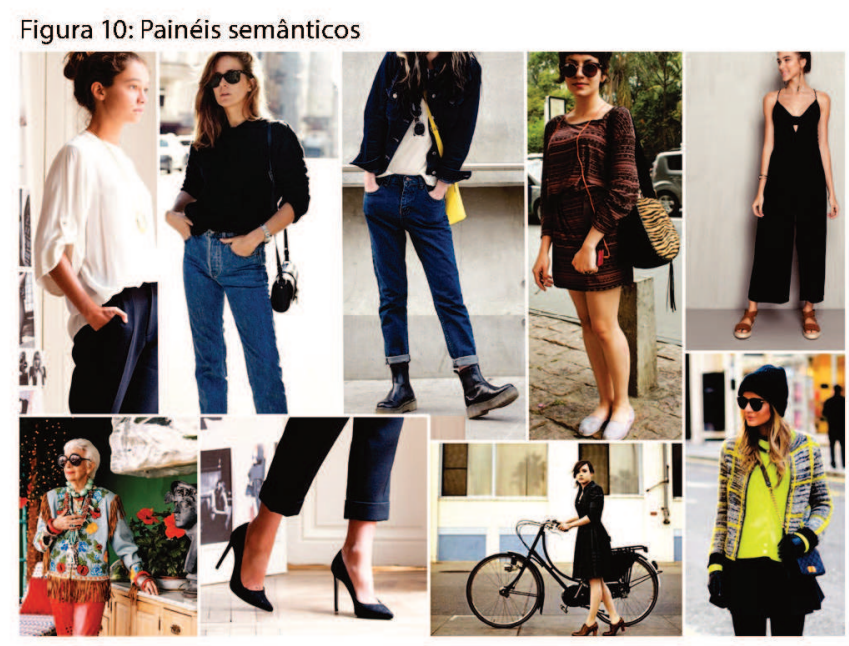




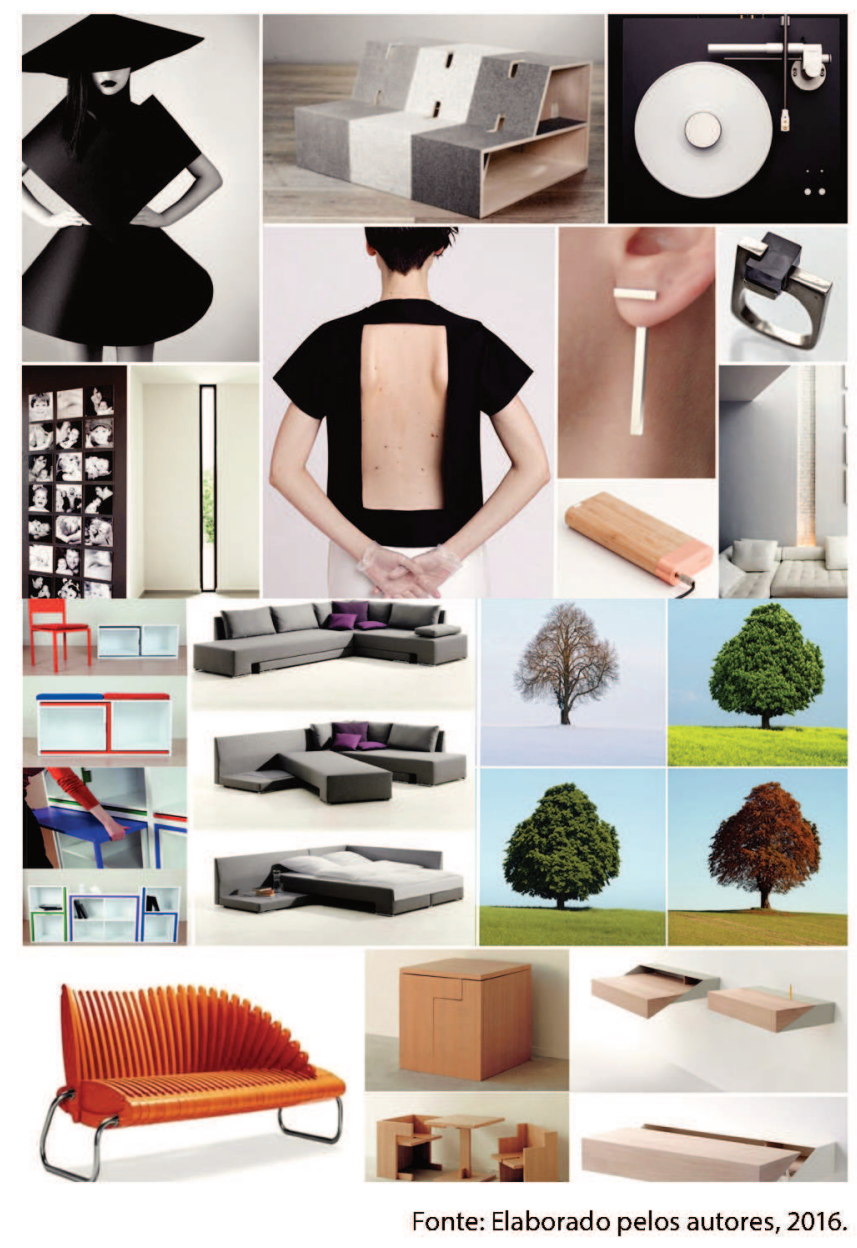

Esses painéis foram o início para a geração de alternativas, o segundo painel, com referência ao minimalismo foi utilizado para as gerações do mobiliário que fará parte da futura loja da marca OMINIMO. Optou-se por gerar por linha, ou seja, gerar todos os móveis e que eles "conversem" entre si, algumas destas linhas podem ser vistas na Figura 11.

Figura 11: Geração de Alternativas

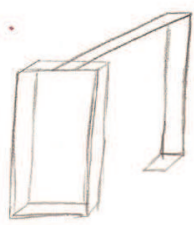

Expositor
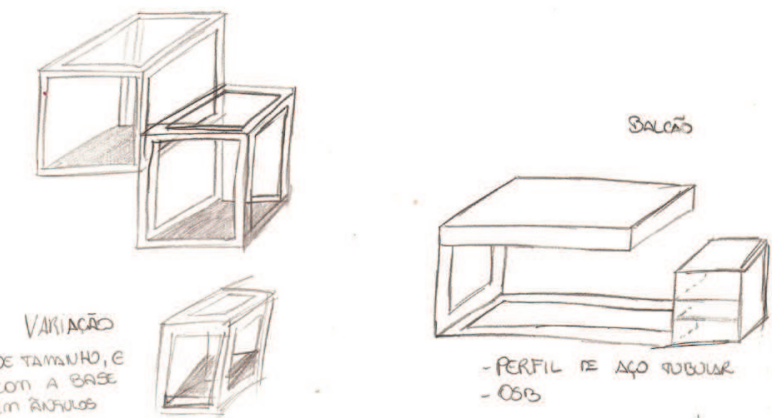

PERFIL IE AYO WUBUUR OSB

\section{WEL D}

PDINEL

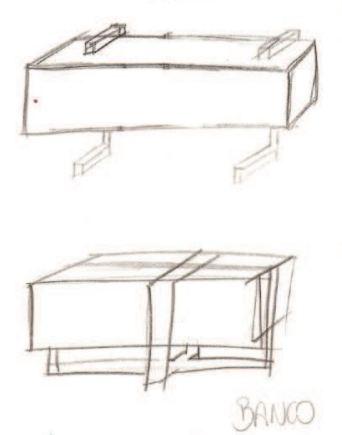

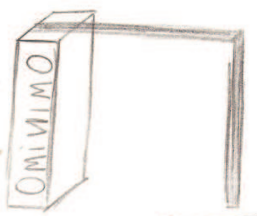

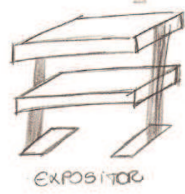

Fonte: Elaborado pelos autores, 2016.

As geraçôes contem traços que foram tirados do painel de tema visual, os ângulos, por exemplo, foram retirados das linhas dos vestidos e as linhas mais retas foram retiradas dos mais variados lugares do painel, o anel e o brinco, que trazem a estética bem minimalista, foram utilizados para os desenhos. Depois de encerrada a geração, foi feito aplicada uma matriz de seleção baseado nos conceitos de Stuart Pugh e é chamada de Pugh Concept Selection, que é apresentada por Pazmino (2015, p.230). Das alternativas apresentadas na geração de alternativas, quatro linhas foram selecionadas e depois numeradas para melhor entendimento (Figura 12).

Figura 12: Linhas selecionadas e a matriz de seleção.

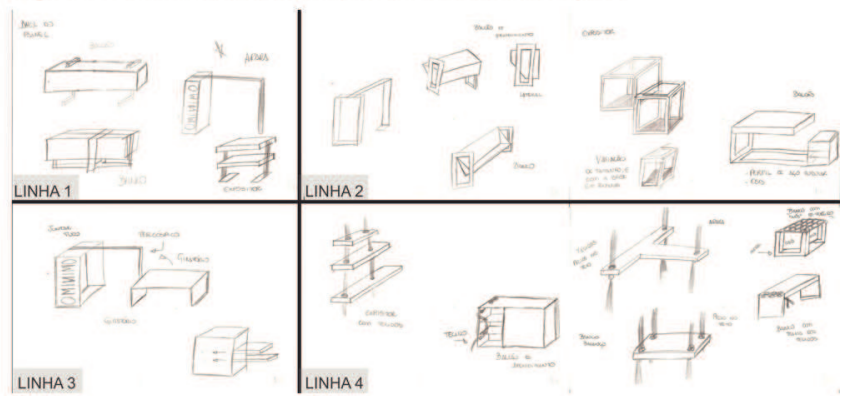

Continua 


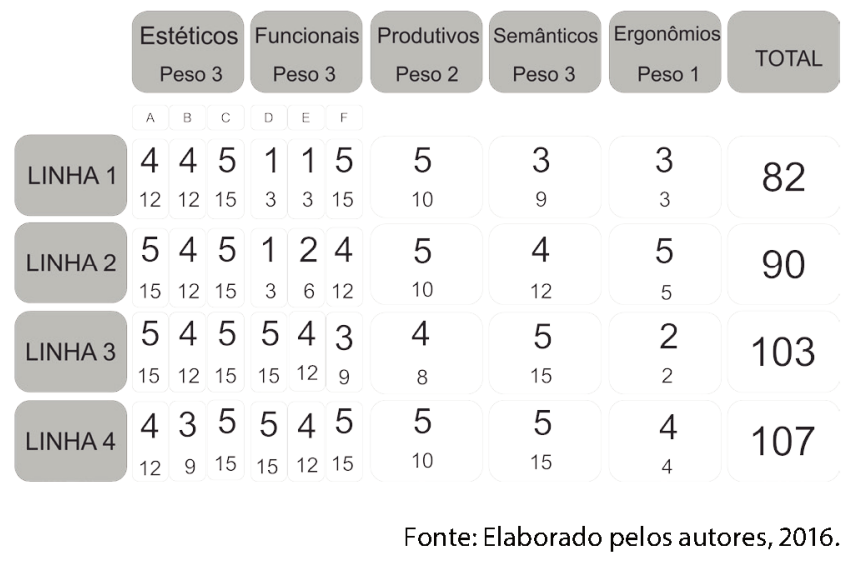

Para realizar a matriz de seleção, foram estabelecidos pesos diferentes aos requisitos: estéticos, funcionais, produtivos, semânticos e ergonômicos. O requisito estético foi subdividido em outros três conceitos; (A) relação com o tema minimalismo; (B) palavras sóbrio, moderno e discreto (palavras retiradas do diferencial semântico); (C) atemporal. O requisito funcional também foi subdividido em: (D) transformável; (E) diferentes modos de utilização; (F) adequação as peças da marca. (As letras de $A$ a $F$, foram utilizadas na matriz de decisão para o melhor entendimento). Os requisitos foram apresentados anteriormente na Tabela 1.

Pesos de 1 a 3 foram colocados em cada requisito, sendo 1, pouco importante e 3 bastante importante. Os requisitos estéticos, funcionais e semânticos com peso 3; produtivos, peso 2 e por fim ergonômico com peso 1. $E$ para as alternativas foram dispostas notas de 1 a 5 , sendo 1 relativo ao requisito pouco atingido e 5 plenamente atingido. As notas dadas foram colocadas na parte superior da caixa e o numero embaixo, já é cálculo da multiplicação realizado. As notas foram estabelecidas pelo autor do trabalho, com auxílio da professora orientadora.

Após a realização deste método, a linha 4 foi selecionada, que corresponde à alternativa que mistura o material OSB com os tecidos das roupas da marca, e para melhor apresentar as alternativas escolhidas, um sketch manual foi realizado com todos os futuros móveis da loja conceito da marca OMINIMO. A Figura 13 apresenta os produtos com as furações para a passagem do tecido que algumas vezes servirá como adorno e outras como estrutura.
Figura 13: Scketchs dos móveis da loja OMINIMO.
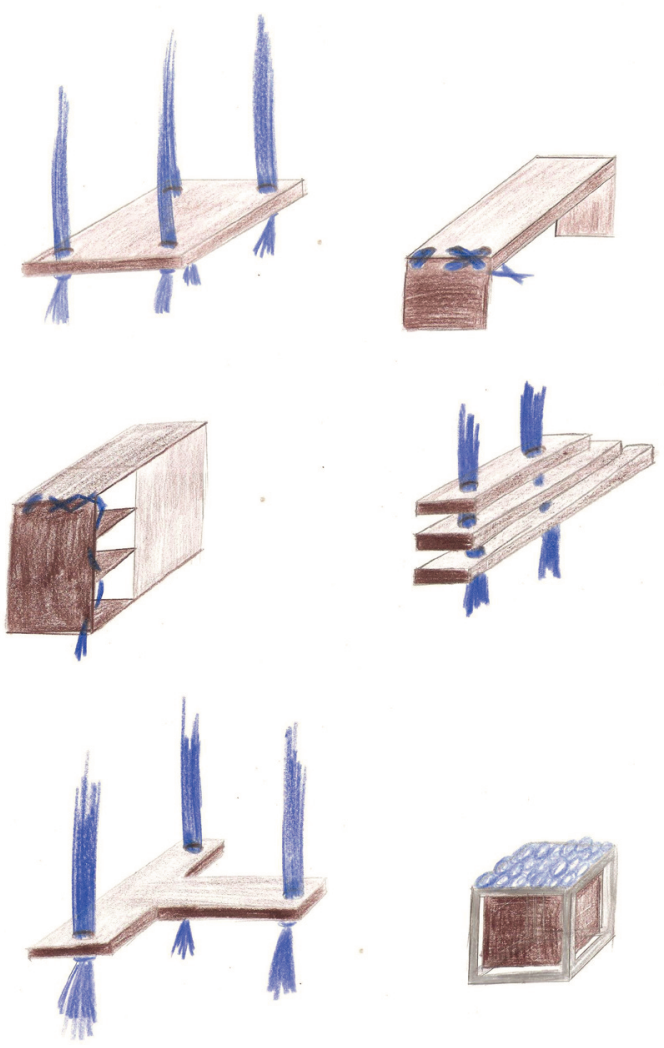

Fonte: Elaborado pelos autores, 2016.

Algumas mediadas foram alteradas para melhor atender as necessidades do usuário, e o balcão de atendimento ficou dividido em três partes para melhor funcionar quando for colocado em uma feira itinerante. O banco baú possui duas alças, para que possa ser carregado mais facilmente. Já as prateleiras, optou-se por deixa-las fixas na loja e não, como havia pensado anteriormente de utiliza-las também nas feiras.

\subsection{Corpo do texto das seções e subseções}

Depois de analisar os possíveis materiais para a realização do modelo físico, optou-se pela utilização do material que é o do produto final, o OSB, juntamente com o tecido das roupas da marca OMINIMO, que é Viscolaycra $(94 \%$ viscose e $6 \%$ elastano). Foi realizado maquete de cada um dos móveis da loja conceito, na escala de 1:3. Foram utilizados três modelos de banco: balanço, banco baú, e tradicional (dois lugares), junto com um modelo de arara, três módulos que juntos formam o balcão de atendimento e as prateleiras, como pode ser visto nas Figuras 14 e 15. 
Figura 14: Balcão de atendimento e seus módulos.

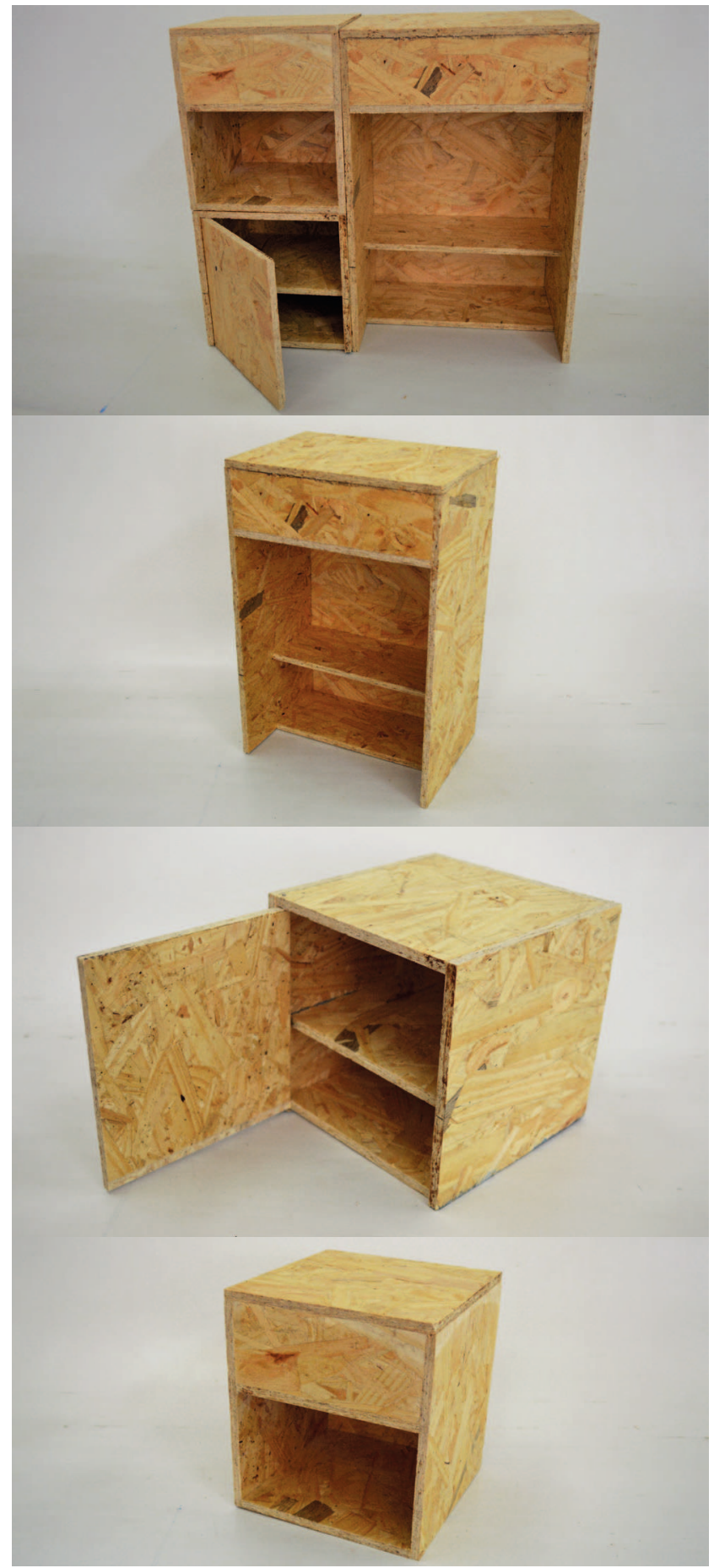

Fonte: Elaborado pelos autores, 2016
Figura 15: Prateleira, arara, banco baú e banco de dois lugares.

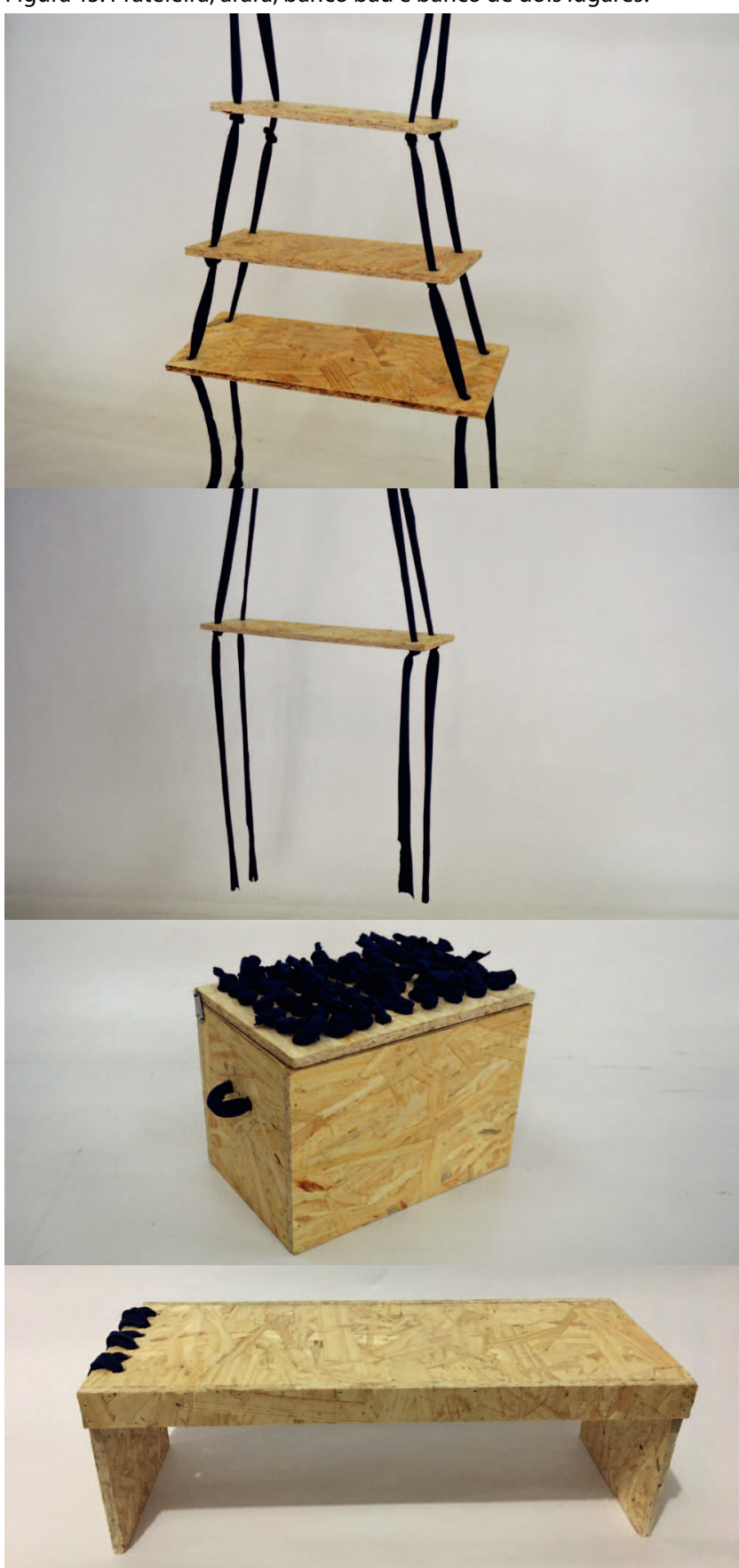

Fonte: Elaborado pelos autores, 2016.

Para dar mais veracidade e realismo ao trabalho, alguns renderes ambientados foram feitos (Figura 16 e 17) realizados. Dois ambientes diferentes, feira itinerante e loja física, foram criados para a aplicação dos móveis projetados.

A arara, por exemplo, na loja é fixa pelos tecidos, mas enquanto tiver em uma feira deve existir uma estrutura onde haverá sustentação; outro exemplo é o banco baú, quando na loja física pode ser utilizado como parte do armazenamento de estoque e pode ser utilizado para acomodação de qualquer item, tanto na feira quanto no transporte. 
Figura 16: Render ambientado da loja.

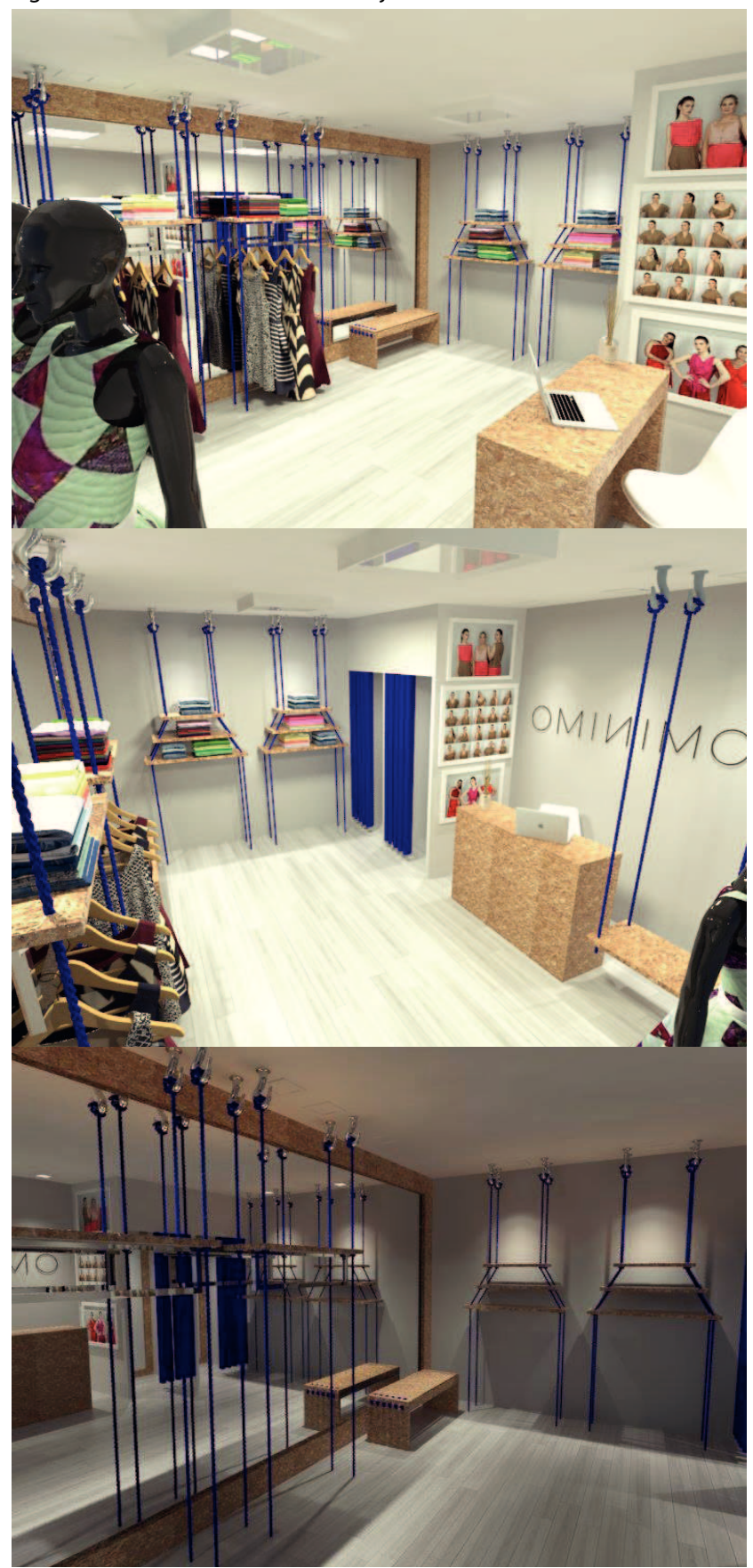

Fonte: Elaborado pelos autores, 2016.
Figura 17: Render ambientado da feira.

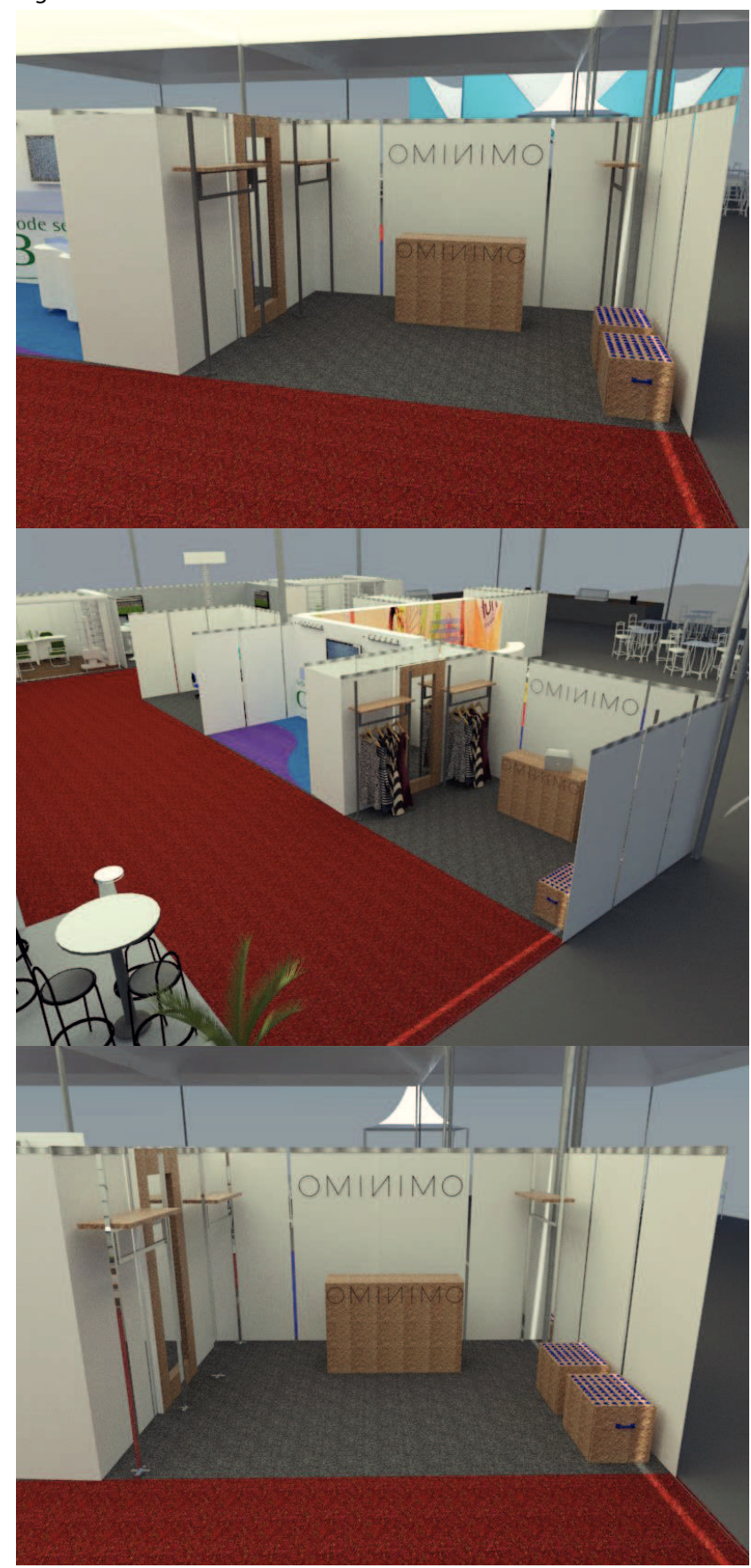

Fonte: Elaborado pelos autores, 2016.

\subsection{Validação de Requisitos}

Como apresentado anteriormente, uma tabela com os requisitos foi feita para que os mesmos servissem como guia durante o projeto do mobiliário da loja. Os requisitos foram divididos em: requisitos estéticos, funcionais, ergonômicos, produtivos, semânticos e ecológicos, e separados em obrigatórios e desejáveis.

Desse modo, o esforço para a consolidação desse projeto, esteve concentrado em atender as reais necessidades dos futuros usuários, mas havendo a possibilidade de 
satisfazer os requisitos desejáveis. Após analisadas a tabela anterior, viu-se que todos os requisitos foram alcançados com o projeto, como pode ser visto na Figura 18.

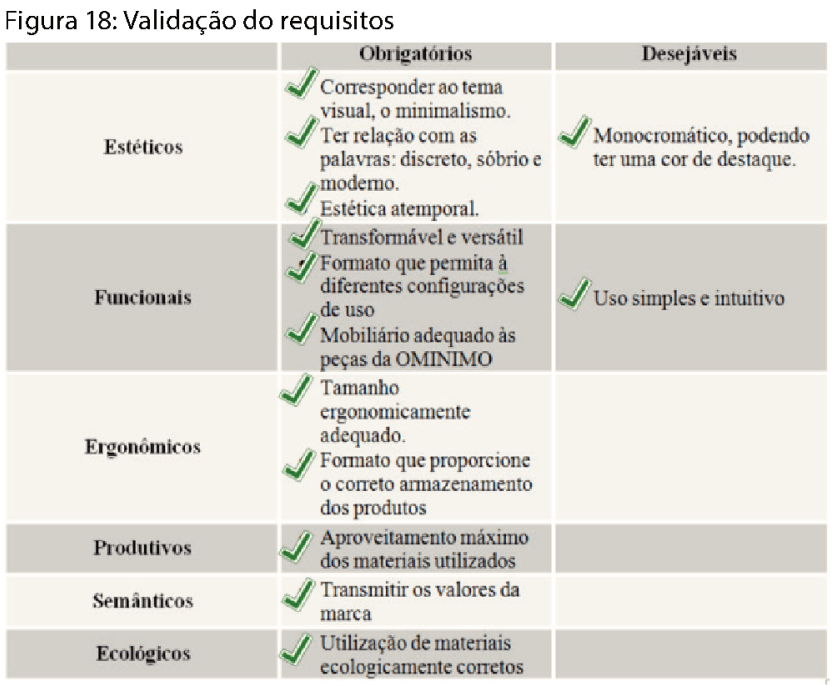

Fonte: Elaborado pelos autores, 2016

Após essa validação, constatou-se que todos os requisitos foram alcançados. Nos requisitos estéticos, todos foram alcançados, o tema minimalismo fica bem explicito ao utilizar linhas retas e o ambiente ser geométrico. Com relação as palavras (discreto, sóbrio e moderno) que foram adquiridas por meio de questionário online, o projeto passou por uma validação online, onde foi lançado um questionário para ter-se a ideia de que os futuros usuários iriam perceber essas palavras no mobiliário e esse quesito foi alcançado; sobre a estética atemporal, foi alcançado também por os produtos serem de fácil transformação; o requisito desejável foi alcançado também, pois o OSB ficou com acabando sem brilho e as cores se dão pelos diferentes tecidos.

\subsection{Resultados e Discussão}

O principal aprendizado adquirido por meio deste trabalho foi a percepção de que o desenvolvimento de um ambiente para espaços comerciais é mais complexo do que se imaginava anteriormente. Neste caso, o estudo direciona-se precisamente para o mobiliário de uma loja, que tem o seu conceito bem definido e esse mobiliário precisa seguir o conceito da marca, que é versatilidade. Além do mobiliário que foi criado, houve a necessidade de estudar e conhecer vários outros fatores que contribuem para o sucesso deste trabalho.

Todo o estudo do referencia teórico forma de alguma importância para o que o projeto em desenvolvimento tivesse uma conclusão adequada. No segundo capítulo deste Trabalho Final de Graduação, estudaram-se ambientes e mobiliário, em que se viu a necessidade da ergonomia e na organização dos móveis para que houvesse uma circulação adequada e que não causasse acidentes e fosse acessível às pessoas com alguma deficiência física.

Em relação aos estudos de iluminação, cores e conforto térmico, se fazem presente neste trabalho para que possam contribuir futuramente na possível construção de loja física. Os estudos de loja conceito que estão no mercado atualmente, foi de suma importância para o conhecimento de diferentes formas de expressar o conceito de cada marca.

Todo o desenvolvimento deste trabalho, traz a concepção da utilização de diretrizes de ecodesign, que foram anteriormente apresentadas no Quadro 1, com o decorrer do trabalho algumas foram levadas mais em consideração do que outras. Em relação às diretrizes de projeto: evitar o dimensionamento excessivo e visar modularidade foram alcançadas, pois cada móvel da loja foi pensado nas necessidades do cliente, que é de apenas uma pessoa fazer o transporte e caber todas as peças em um carro; na seleção de materiais: a redução do materiais foi alcançada, pois utilizou-se apenas OSB e tecidos que a marca utiliza para a fabricação das suas peças, eliminou-se também a utilização de materiais tóxicos e poluentes e por os móveis serem todos com cortes retos e sem curvas, os resíduos são mínimos.

Quando considerado as diretrizes da etapa de fabricação, foi considerado o design para desmontagem, pois as uniões são feitas com parafusos, sendo assim não unidas permanentemente. Duas das diretrizes de ecodesign na etapa de distribuição não podem ser afirmadas que foram ou não alcançadas, pois só seria possível o projeto fosse feito de modo real, nesta etapa a única que foi alcançada foi a de facilitar o transporte das peças. Na etapa de utilização, o ciclo de vida de cada produto é ampliado, e a reposição e manutenção quando necessária é fácil, pois o material principal, OSB, é de fácil acesso. Finalmente, na etapa do fim da vida útil, facilitar a separação das partes e dos materiais, e estender o máximo o ciclo de vida dos materiais forma também alcançados.

Após grande pesquisa de referencial teórico, o capítulo quatro tratou da metodologia que iria ser necessária para a resolução deste projeto, análises essas que foram fundamentais para saber as necessidades dos usuários, entrevistas com especialistas que ajudaram a sanar duvidas quanto a projetos de ambientes. E outro fator motivador foi de conhecer o e estabelecer relação com o designer da marca, que disse suas necessidades e suas vontades para o desenvolvimento da loja conceito. 
Das análises realizadas as que foram fundamentais foram: a de uso e a da necessidade; ambas colaboraram com a percepção das necessidades do usuários, para que o projeto assuma uma estrutura de trabalho ampliada e de fácil uso. A pesquisa online, que gerou o infográfico (Figura 36), colaborou para assim iniciar a geração de alternativas.

A modelagem 3D, por meio do software SolidWorks ajudou a sanar algumas duvidas sobre o dimensionamento de cada produto e como poderia fazer com que eles fossem versáteis. Ambientes onde futuramente os móveis podem ser instalados foram criados para trazer mais realidade e veracidade ao trabalho. Sua materialização deu-se por meio de maquete com os materiais do produto final. Foram realizados modelos físicos de todos os móveis desenhados e que poderão estar em um futuro projeto.

\subsection{Considerações Finais}

O envolvimento de duas áreas de design como o design de interiores e a moda, foi um desafio interessante; sempre houve vontade grande de poder uni-las e poder realizar algum trabalho relacionado a espaços comerciais.

Por meio da pesquisa teórica e da metodologia de projeto, conseguiu-se solucionar o principal problema que foi apresentado nesse trabalho, que era de aliar a versatilidade, presente nas roupas das marcas, junto com o mobiliário da loja conceito; e ainda fazer com que o mobiliário fosse utilizado em dois ambientes diferentes: loja física e feiras itinerantes.

A pesquisa teórica foi construída buscando entender conceitos, alcançar alguns objetivos relacionados a construção de espaços públicos e normas para a realização de projetos de design de interiores. Na metodologia projetual, as análises foram de suma importância para atender ao público-alvo da loja e poder assim, na geração de alternativas e seleção da alternativa encontrar a melhor solução de cada móvel do projeto.

Acredita-se que tanto por meio das pesquisas realizadas para o referencial teórico quanto para as análises realizadas durante o desenvolvimento, conseguiram sanar e atender os objetivos específicos e objetivo geral deste trabalho, desse modo cumprindo o desenvolvendo uma loja conceito, com mobiliário versátil e enfoque nos materiais ecologicamente corretos.

Outro item que contribuiu bastante para que o trabaIho fosse realizado foi de poder eleger as etapas de cada metodologia, fazendo com que o trabalho faça uso apenas das fases que realmente importam para alcançar o resultado final.
Várias dificuldades foram encontradas durante o trabalho; o fato de ter trabalho apenas uma vez com interiores durante a graduação, na disciplina de Mobiliário II; segundo, pelo conceito da marca e conseguir alia-lo ao mobiliário; houve-se dificuldade em saber dimensionamento de lojas de shopping, pois os mesmos não poderiam ou não queriam liberar as plantas baixas desses ambientes; e também o fato de a marca ser nova no mercado, criada em março de 2016, e não ser conhecida do grande público.

Outro fator que contou para o sucesso deste trabalho foi que o projeto pode vir a se realizar, pois o cliente, a marca OMINIMO, é real e possui as necessidades bem definidas, com o conceito bem explicito no mercado, e esse difícil e complexo de ser alcançado. Os móveis projetados estão realmente conectados com os princípios da marca, e que podem ser utilizados.

Para dar continuidade ao trabalho, avalia-se a necessidade de um maior estudo sobre ergonomia para ambientes comerciais, tais como iluminação e circulação de pessoas portadoras de deficiência.

Portanto, desenvolveu-se um projeto que, além de sua forma inovadora e atual, interage com a moda, sendo possível de instalação em vários ambientes. Desse modo, buscaram-se soluções de design que melhorasse a qualidade de vida do usuário, minimizando seus desgastes ao realizar a tarefa, proporcionando um maior bem-estar e conforto e, ainda, compondo um ambiente, onde o conceito máximo da marca pode apresentado, e com o intuito de trazer experiências diferentes para cada usuário, sendo ele cliente ou possível funcionário da loja, mudando o dia a dia das pessoas que passem pelo ambiente loja conceito.

\section{AGRADECIMENTOS}

Sem o auxílio de diversas pessoas, esse trabalho não poderia ser realizado. Agradeço aos meus pais por todo o apoio. Não tenho palavras para agradecer a minha orientadora e também autora deste trabalho, professora Mariana Piccoli. Meu muito obrigado a banca de professoras, Salette Marchi e Círia Moro, e o meu agradecimento ao idealizador da marca OMINIMO, o designer Rafael Körbes, que disponibilizou sua marca para fazer parte deste projeto.

\section{REFERÊNCIAS}

BAXTER, M. Projeto de Produto: guia prático para o design de novos produtos. São Paulo: Edgard Blücher, 1998 
BONSIEPE, G. Metodologia Experimental: Desenho Industrial. Brasília: CNPq/Coordenação Editorial, 1984.

CARDOSO, R. Design para um mundo complexo. São Paulo: Cosac Naify, 2012. 264p.

GURGEL, M. Projetando espaços: guia de arquitetura de interiores para áreas comerciais. 1. ed. São Paulo, SP: Editora Senac São Paulo, 2005. 223 p.

HCD. Human Centered Design: Kit de Ferramentas. 2 ed. 2010. Disponível em: <https://hcd-connect-production.s3.amazonaws.com/toolkit/en/portuguese_download/ideo_hcd_toolkit_complete_portuguese.pdf $>$. Acesso em: 16 mar. 2016.

KAZAZIAN, T. Haverá a idade das coisas leves: design e desenvolvimento sustentável. 2. ed. Tradução de Eric Roland Rene Heneault. São Paulo: Senac, 2005.

LIMA, M. Introdução aos Materiais e Processos para Designers. Rio de Janeiro: Ciência Moderna, 2006.

LÖBACH, B. Design Industrial: bases para a conBlücher, 2001.

LUBIANCA, A. Cuidados ao projetar um espaço comercial. Disponível em: <http://www.planobaselubianca.com.br/cuidados-ao-projetar-um-ambiente-comercial> Acesso em: 12 abr. 2016.

MELISSA. Melissa é mais do que sapato. É mais do que plástico. É expressão criativa. 2016. Disponível em: <https://www.melissa.com.br/galerias/sp> Acesso em: 11 abr. 2016.

MUNDA DAS MARCAS. Melissa. Disponível em: $<$ http://mundodasmarcas.blogspot.com.br/2006/07/melissa-moda-em-plstico.html> Acesso em: 11 abr. 2016.

OMINIMO. \#useominimo. 2016. Disponível em: <http://ominimo.com.br/> Acesso em: 11 mar. 2016.

PAZMINO, A. Como se cria: 40 métodos para design de produto. São Paulo: Blucher, 2015.

PICCOLI, M. A Reutilização de Resíduos Industriais como Base para o Desenvolvimento de Produtos.

2010, 132p. Trabalho de Conclusão de Curso - Curso de Desenho Industrial/Projeto de Produto - Universidade Federal de Santa Maria, Santa Maria, 2010.

REVISTA GLAMOUR. Melissa pra inglês ver! A marca inaugura loja conceito em Londres. Disponível em: < http://revistaglamour.globo.com/Moda/Fashion-news/ noticia/2014/10/melissa-pra-ingles-ver-marca-inaugura-loja-conceito-em-londres.html> Acesso em: 11 abr. 2016.

VIES DESIGN. Loja conceito: nova aposta das marcas para atrair consumidores. 2014. Disponível em: <http:// www.viesdesign.com.br/2014/04/loja-conceito-nova-aposta-das-marcas.html> Acesso em: 20 mar. 2015. 